\title{
Prospective Observational Study on Evaluation of Cardiac Dysfunction Induced during the Weaning Process
}

\author{
${ }^{1}$ Havaldar Amarja, ${ }^{2}$ Krishna Bhuvana, ${ }^{3}$ Sampath Sriram
}

\begin{abstract}
Context: Weaning induced cardiac dysfunction can occur without underlying heart disease. Changes in intrathoracic pressure, systemic vascular resistance, preload and afterload leading to heart-lung interactions are the possible explanatory mechanisms
\end{abstract}

Aims: The aim of the current study was whether the assessment and identification of cardiac dysfunction induced during the weaning process could predict the outcome of extubation.

Settings and design: A prospective observational study with convenience sampling method was conducted from May 2015 to April 2016 after institutional ethical committee approval (ref 161/2015)

Materials and methods: Patients over eighteen and planned for extubation were included. Weaning method used was a spontaneous breathing trial (SBT) by pressure support-positive end-expiratory pressure (PS-PEEP). Baseline characteristics, weaning, and echocardiography parameters were collected pre extubation. Post-extubation echocardiographic parameters were collected within six hours as per the protocol. The primary outcome was extubation failure (reintubation within 48 hours). Secondary outcomes were ICU length of stay and ICU mortality.

Statistical analysis: Statistical method used is STATA ${ }^{\text {TM }}$ (Version14, College Station TX).

Results: Out of one hundred and sixty-one patients, twenty-one failed extubation (13.04\%). Pre-extubation echocardiographic parameters were similar in two groups except for preexisting LV systolic dysfunction. Post-extubation E/e` (9.30 vs. $7.71 \mathrm{p}$ $=0.018$ ) was higher in the extubation failure group. Extubation failure group had higher ICU length of stay and ICU mortality.

Conclusion: In our study E/e during a weaning trial did not predict extubation success. Cardiac dysfunction induced during weaning may get masked during weaning and manifests postextubation. This needs to be verified in subsequent studies.

Key Messages: Cardiac dysfunction induced during the weaning process may get masked and manifests post-extubation. Echocardiographic assessment during the weaning process and post-extubation helps to evaluate and identify the patients at risk of reintubation.

\footnotetext{
${ }^{1}$ Assistant Professor, ${ }^{2,3}$ Professor

${ }^{1-3}$ Department of Critical Care Medicine, St. John's Hospital, Bangalore, Karnataka, India
}

Corresponding author: Havaldar Amarja, Assistant Professor, Department of Critical Care Medicine, St. John's Hospital, Bangalore, Karnataka, India, Mobile: +919036082112, e-mail: amarjahavaldar@rediffmail.com
Keywords: Cardiac dysfunction, Doppler echocardiography, PS-PEEP, Spontaneous breathing trial, Weaning.

How to cite this article: Amarja H, Bhuvana K, Sriram S. Prospective Observational Study on Evaluation of Cardiac Dysfunction Induced during the Weaning Process. Indian Journal of Critical Care Medicine, January 2019;23(1),15-19.

\section{Source of support: $\mathrm{Nil}$}

Conflict of interest: None

\section{INTRODUCTION}

Weaning the patient from ventilator support is crucial, and the process needs to be initiated at the earliest and when there is a resolution of primary pathology. ${ }^{1,2}$ Weaning failure is defined as failure to pass SBT or the need for reintubation within 48 hours following extubation. The incidence of extubation failure is around 2 to $25 \%{ }^{3,4}$ Extubation failure is associated with prolonged ICU stay and mortality hence it's prediction is important. ${ }^{3}$

Cardiac dysfunction induced by weaning can occur without underlying heart disease..$^{5-8}$ The change in intrathoracic pressure during the process of weaning can precipitate cardiac dysfunction. ${ }^{6-8}$ Mechanisms which have been proposed include (a) increased adrenergic tone which results in redistribution of venous blood from the unstressed volume towards the stressed volume; (b) an increase in the systemic venous pressure gradient, central blood volume, and RV preload; (c) changes in intra-thoracic pressure resulting from the transition from positive pressure ventilation to spontaneous breathing, can increase LV preload, afterload, systolic arterial pressure, and heart rate. ${ }^{5}$

In a small trial, Lemaire et al. noted elevation of pulmonary artery occlusion pressure (PAOP) in patients who failed spontaneous breathing trials (SBT). ${ }^{9}$ The conclusion of this study was not easily generalizable as the study included difficult to wean chronic obstructive pulmonary disease (COPD) patients and the study was performed in only fifteen patients. Similar trials have been done in the past in subgroups of patients such as COPD, patients with neurological disease, without underlying heart disease or patients without arrhythmia and the external validity of such trials is limited. ${ }^{10,11}$ Recent meta-analysis evaluating diastolic dysfunction as a cause for weaning failure showed higher E/e` was associated with weaning failure and taking into account wide heterogeneity in the 
criteria for diastolic dysfunction in trials included, these findings could not be easily generalizable. ${ }^{11}$

Conventional weaning parameters such as rapid shallow breathing index (RSBI), a value of less than one hundred and five cannot identify the possibility of extubation failure. ${ }^{12,13}$ The need for parameters which can guide treating physicians in deciding for extubation has been highlighted by studies. ${ }^{14,15}$

The literature on cardiac dysfunction induced by weaning in a general ICU population in Indian settings is scanty. The predominantly weaning method used in ICU's is PS with PEEP. During the process of weaning heart, lung interactions can cause cardiac dysfunction, and it affects the outcome of extubation. With an increase in the incidence of cardiac co-morbidities and elderly population the study on cardiac dysfunction induced by weaning is indicated and appropriate. Cardiac dysfunction can be assessed noninvasively by echocardiography at the bedside. ${ }^{16-19}$ The aim of the current study was whether the assessment and identification of cardiac dysfunction induced during the weaning process could predict extubation success in the general ICU population.

\section{SUBJECTS AND METHODS}

Formal institutional ethical committee approval was obtained before initiating the study (ref no 161/2015). The study was conducted for a duration of 1 year from May 2015 to April 2016. It was a prospective, observational study conducted in the thirty bedded ICU of a large university medical center. Patients were enrolled and included, after obtaining consent from patients or legally acceptable representatives. All patients above eighteen years of age, who were planned for extubation as per the decision of treating team was included in the study. Tracheostomised and pregnant patients were excluded. Weaning method used in the study was pressure supportpositive end-expiratory pressure (PS with PEEP). After successful completion of SBT by PS with PEEP as per the ICU protocol, patients planned for extubation based on treating physician's decision were included in the study. The convenience sampling method was used for patient selection. Patients with preexisting comorbid illnesses were included in the prespecified subgroups. Comorbidities were classified based on ICD 10 (International statistical classification of diseases). Patients with preexisting cardiac illnesses were also part of our study

All measurements were performed by the first author to avoid inter-observer bias. An average of three recordings over five minutes was taken to avoid intraobserver bias. Baseline characteristics, weaning, and echocardiography parameters were collected pre extubation. The extubation was performed immediately after the collection of parameters. Repeat echocardiographic assessment was planned as these patients were followed up till 48 hours and the primary outcome of the study was extubation failure (reintubation within 48 hours). Repeat echocardiography after six hours post-extubation was planned as per the protocol to look for any change in the echocardiographic parameters. All patients were followed until discharge from ICU. Secondary outcomes were mortality and ICU length of stay.

Conventional weaning parameters like respiratory rate, tidal volume, $\mathrm{RSBI}, \mathrm{FiO}_{2}, \mathrm{PEEP}, \mathrm{PaO}_{2} / \mathrm{FiO}_{2}$ were collected. ${ }^{6}$ Acute Physiology, Age and chronic health evaluation score (APACHE II) was calculated from records of the first twenty-four hours of ICU admission. The cumulative fluid balance of 3 days before extubation was calculated. Hemoglobin on the day of extubation measured on ABG machine was collected. All patients were followed up until ICU discharge. Extubation failure was defined as the requirement of mechanical ventilation support within 48 hrs of extubation. ${ }^{5}$

Echocardiographic measurements: All measurements were done using a Sonosite ${ }^{\mathrm{TM}}$ Edge portable machine with a $2.5 \mathrm{MHz}$ probe and inbuilt cardiac calculation software. LV systolic function was assessed qualitatively by visual gestalt method taking into account LV size, contractility and thickening of the various segments and classified into good, mild, moderate, moderate to severe and severe LV dysfunction. Qualitative assessment of systolic function was done due to ease of its use. LV diastolic dysfunction was assessed by transmitral flow velocity. Early filling phase (E), late filling phase (A) and deceleration time (DCT) were measured. E/ A was calculated. Assessment of mitral annular flow velocity was done using tissue Doppler imaging at the lateral mitral annulus. $\mathrm{e}^{\prime}$ and $a^{\prime}$ were measured. In patients having regional wall motion abnormalities (RWMA), both lateral and septal mitral leaflet velocities were measured and averaged. The right ventricular systolic function was assessed using tricuspid annular plane systolic excursion (TAPSE) and inferior vena cava (IVC) diameter was measured. E/A, E/e`was calculated.

\section{RESULTS}

Statistical methods STATA ${ }^{\mathrm{TM}}$ (Version14, College Station TX) was used for statistical analysis. Data were expressed as mean (SD) or median (Interquartile range IQR) as appropriate. Bivariate analysis of primary outcome versus independent characteristics was done using $\chi^{2}$ test for categorical variables and ' $t$ 'test (Satterwhite's for unequal variance) for continuous data. 'Mann-Whitney $\mathrm{U}^{\prime}$ test was used for non-parametric continuous variables. A standard 95\% confidence limit and a p-value at 0.05 were used for assessing statistical significance. 
Prospective Observational Study on Evaluation of Cardiac Dysfunction Induced during the Weaning Process

\begin{tabular}{llll}
\hline \multicolumn{4}{c}{ Table 1: Baseline Parameters } \\
\hline $\begin{array}{l}\text { Baseline } \\
\text { parameters }\end{array}$ & $\begin{array}{l}\text { Extubation } \\
\text { mean }(S D) /\end{array}$ & $\begin{array}{l}\text { Extubation } \\
\text { failure } \\
(n=21)\end{array}$ & \\
Median $(I Q R)$ & $(n=140)$ & $51.85(22.95)$ & 0.8 \\
\hline Age & $47.40(17.27)$ & $13 / 8$ & 0.64 \\
Gender (M/F) & $74 / 66$ & $20.85(5.65)$ & 0.12 \\
APACHE II & $18.02(6.61)$ & $4(2-5)$ & $0.01^{*}$ \\
Days on & $2(1-4)$ & & \\
ventilator & & $11(52.38)$ & 0.08 \\
Cardiac disease & $46(32.85)$ & $5(23.80)$ & 0.26 \\
Renal disease & $20(14.28)$ & $0(0)$ & 0.20 \\
$\begin{array}{l}\text { Respiratory } \\
\text { Endocrine }\end{array}$ & $10(7.14)$ & $9(42.85)$ & 0.26 \\
Cumulative fluid & $1943(480.71)$ & $2289(912-3416)$ & 0.38 \\
balance & & & \\
*significant $p<0.05$ & &
\end{tabular}

The variables identified as significant in the bivariate analysis were used as independent variables and outcomes were used as dependent variables to develop a predictive model using logistic regression. Measurements obtained pre and post-extubation were analyzed using conditional logistic regression.

Total one eighty patients were screened. Nineteen patients were excluded due to poor echo window $(10.5 \%)$. Out of one sixty-one patients, one forty $(86.95 \%)$ patients were successfully extubated and twenty-one $(13.04 \%)$ patients had extubation failure. The summary baseline characteristics, for reintubated and successfully extubated patients, were collected (Table 1). Baseline characteristics were comparable between patients with extubation success and failure group.

The measured echocardiographic parameters were compared pre and post-extubation for both failed and successful extubations (Table 2 and 3). Echocardiographic assessment of systolic function was done by visual gestalt method. Out of 161 patients, 20(12.42\%) had severe LV systolic dysfunction. Diastolic dysfunction by transmitral flow velocity using pulsed wave Doppler (PWD) showed $\mathrm{E} / \mathrm{A}$ of 1.25 in successful and E/A1.30 in failed extubation

Table 3: Post-extubation echocardiographic assessment

\begin{tabular}{|c|c|c|c|}
\hline $\begin{array}{l}\text { Postextubation } \\
\text { ECHO Mean } \\
\text { (SD)/Median } \\
\text { (IQR) }\end{array}$ & $\begin{array}{l}\text { Extubation } \\
\text { success } \\
(n=140)\end{array}$ & $\begin{array}{l}\text { Extubation } \\
\text { failure } \\
(n=21)\end{array}$ & $p$-value \\
\hline $\mathrm{E}(\mathrm{cm} / \mathrm{sec})$ & $86.04(20.41)$ & 99.08 (35.68) & 0.11 \\
\hline $\mathrm{A}(\mathrm{cm} / \mathrm{sec})$ & 72.52 ( 20.24) & 77.18 (38.27) & 0.59 \\
\hline E/A & $1.18(0.91-1.53)$ & $1.20(0.93-1.75)$ & 0.21 \\
\hline $\mathrm{DCT}(\mathrm{ms})$ & $121.60(36.46)$ & $114.98(32.77)$ & 0.40 \\
\hline $\mathrm{e}^{\prime}(\mathrm{cm} / \mathrm{sec})$ & $11.71(3.20)$ & $10.78(2.83)$ & 0.18 \\
\hline$a^{\prime}(\mathrm{cm} / \mathrm{sec})$ & $10.0(2.72)$ & $9.51(2.88)$ & 0.46 \\
\hline$E / e^{`}$ & $7.71(2.72)$ & $9.30(2.72)$ & $0.018^{*}$ \\
\hline $\begin{array}{l}\text { TAPSE }(\mathrm{cm} / \\
\mathrm{sec})\end{array}$ & $1.95(0.49)$ & $1.70(0.70)$ & 0.15 \\
\hline IVC (cm) & $1.66(0.52)$ & $1.65(0.41)$ & 0.9 \\
\hline
\end{tabular}

*significant $p<0.05$

Table 2: Pre-extubation echocardiographicassessment

\begin{tabular}{|c|c|c|c|}
\hline $\begin{array}{l}\text { Pre extubation } \\
\text { ECHO } \\
\text { Mean (SD)/ } \\
\text { Median (IQR) }\end{array}$ & $\begin{array}{l}\text { Extubation } \\
\text { success } \\
(n=140)\end{array}$ & $\begin{array}{l}\text { Extubation } \\
\text { failure } \\
(n=21)\end{array}$ & $p$-value \\
\hline $\mathrm{E}(\mathrm{cm} / \mathrm{sec})$ & $81.91(19.27)$ & $92.52(24.94)$ & 0.07 \\
\hline $\mathrm{A}(\mathrm{cm} / \mathrm{sec})$ & 69.95 (19.61) & 77.92 (26.39) & 0.19 \\
\hline$E / A$ & $1.25(0.47)$ & $1.30(0.55)$ & 0.72 \\
\hline DCT (ms) & $119.22(38.18)$ & $116.48(36.04)$ & 0.75 \\
\hline$e^{\prime}(\mathrm{cm} / \mathrm{sec})$ & $11.38(3.24)$ & $11.43(3.17)$ & 0.95 \\
\hline$a^{\prime}(\mathrm{cm} / \mathrm{sec})$ & $9.56(2.78)$ & $10.16(2.43)$ & 0.31 \\
\hline$E / e^{\prime}$ & $7.68(2.79)$ & $8.21(2.95)$ & 0.45 \\
\hline TAPSE $(\mathrm{cm} / \mathrm{sec})$ & $1.84(0.53)$ & $1.83(0.32)$ & 0.95 \\
\hline IVC $(\mathrm{cm})$ & $1.6(0.3)$ & $1.6(0.4)$ & 0.8 \\
\hline $\begin{array}{l}\text { Severe LV } \\
\text { dysfunction }\end{array}$ & $9 / 131$ & $7 / 14$ & $<0.001^{*}$ \\
\hline
\end{tabular}

group. Mitral annular flow velocity by tissue Doppler imaging (TDI) showed pre extubation E/e` was not statistically significant in extubation success and failure group (7.68 vs. $8.21 \mathrm{p}=0.45$ ). There was no echocardiographic parameter which could be measured pre-extubation which was statistically significant between the two groups except for pre-existing severe LV dysfunction.

In the parameters measured post-extubation, $\mathrm{E} / \mathrm{e}^{\prime}$ was statistically significant between extubation success and failure group (7.71 vs. $9.30 \mathrm{p}=0.018)$ (Table 3). The ventilatory parameters were not statistically significant between the two groups (Table 4). In secondary outcomes, patients in the extubation failure had higher ICU length of stay and mortality (Table 5). Attempts to fit a logistic model did not identify any combination of co-variates (Echo and respiratory) which could predict successful extubation. Similarly, conditional logistic regression could not identify parameters which could predict extubation success.

\section{DISCUSSION}

Echocardiographic assessment before extubation in unselected ICU population is feasible and practical. In our study, there were only 19 patients $(10.5 \%)$ in which echocardiographic assessment could not be done. As compared to the previous study by Lemaire et al., where PAOP was measured, in our study, cardiac dysfunction

\begin{tabular}{llll}
\multicolumn{4}{c}{ Table 4: Ventilator parameters } \\
\hline $\begin{array}{l}\text { Ventilator } \\
\text { parameters }\end{array}$ & $\begin{array}{l}\text { Extubation } \\
\text { success } \\
(n=140)\end{array}$ & $\begin{array}{l}\text { Extubation } \\
\text { failure } \\
(n=21)\end{array}$ & $p$-value \\
\hline $\begin{array}{l}\text { TIDAL VOLUME } \\
(\mathrm{mL})\end{array}$ & $\begin{array}{l}451.69 \\
(118.56)\end{array}$ & $421.66(91.81)$ & 0.19 \\
& & & \\
RR & & & \\
RSBI & $20.09(5.70)$ & $22.85(5.96)$ & 0.05 \\
PS & $68.97(30.64)$ & $66.41(23.20)$ & 0.65 \\
PEEP & $8.94(2.43)$ & $9.57(3.57)$ & 0.44 \\
\hline
\end{tabular}


Table 5: Primary and Secondary outcomes

\begin{tabular}{llll}
\hline $\begin{array}{l}\text { Primary and } \\
\text { Secondary }\end{array}$ & & & \\
Outcome & $\begin{array}{l}\text { Extubation } \\
\text { success } \\
\text { Mean }(S D) /\end{array}$ & $\begin{array}{l}\text { Extubation } \\
\text { failure }\end{array}$ & \\
Median $(I Q R)$ & $(n=140)$ & $(n=21)$ & $p$-value \\
\hline Extubation & $140(86.95 \%)$ & $21(13.04 \%)$ & \\
ICU LOS & $6(4-8)$ & $13(8-19)$ & $<0.001^{*}$ \\
ICU mortality & $11 / 129(7.8 \%)$ & $11 / 10(52.3 \%)$ & $<0.001^{*}$ \\
\hline
\end{tabular}

*significant $p<0.05$

was assessed non-invasively by echocardiography.

Previous trials showed E/e' was the echocardiographic parameter which was a good predictor of extubation success. The recent study by Pappanikolaou et al. showed E/e at lateral mitral leaflet of $>7.8$ may identify patients at high risk of weaning failure. ${ }^{20}$ In the study by Moschietto et al, patients were weaned by SBT with PS and showed higher $\mathrm{E} / \mathrm{e}$ ' in extubation failure group. LV systolic dysfunction was not found as a cause for weaning failure. ${ }^{21}$ A recent study also showed isolated diastolic dysfunction was associated with prolonged weaning. ${ }^{22}$ In our study pre extubation assessment E/e`(7.68 vs $8.21, \mathrm{p}=0.45$ ) was not found as a statistically significant parameter but pre-existing LV systolic dysfunction was found to be a statistically significant parameter.

The possible reason for the difference in the results of our study as compared to previous is the method used for weaning. SBT with T-piece was the weaning method used in the majority of the previous studies. ${ }^{19}$ SBT with PS-PEEP helps in overcoming load dependent diastolic heart failure and causes a reduction in LV preload and LV afterload thereby improving LV emptying. As a result of which cardiac dysfunction during weaning gets masked and becomes more evident post-extubation as shown in the present study. ${ }^{23,24}$ In our study, cardiac parameters measured post-extubation showed E/e` was higher in the group who failed extubation (9.30 vs $7.71 \mathrm{p}=0.018$ ) and was statistically significant.

Reintubation is associated with increased length of ICU stay and mortality, and it is important to time the extubation appropriately. ${ }^{2-4}$ The current study has shown that cardiac dysfunction possibly precipitated by the withdrawal of pressure support and peep can be picked up by post-extubation echocardiographic assessment.

The limitation of the current study was that all readings were collected by a single observer. The effect of inter-observer variability could not be assessed. Patients who successfully completed SBT were included, and patients were not classified based on simple, difficult and prolonged weaning as extubation was the primary outcome of the study. Days on a ventilator was one of the baseline variables which was statistically different in the two groups, but it was a non-significant covariate in the logistic model. Patients having higher E/e` post- extubation had higher chances of reintubation. For the results of this study to be generalizable, a larger study in which the echo parameters are collected reliably and with sufficient precision by multiple observers and involving repeated echocardiographic assessment is indicated. Different weaning methods and its effect on extubation success need to be evaluated in subsequent studies.

Recent studies have highlighted the importance of the preload condition of the right and left ventricle and the effect of passive leg raising and fluid removal on weaning-induced cardiac dysfunction. ${ }^{25,26}$

Future studies involving pre extubation assessment of Cardia, Lung, Pleura, and Diaphragm, is required to help the clinician in identifying patients at risk of extubation failure due to multiple factors. ${ }^{27}$

\section{CONCLUSION}

In our study, echocardiographic measurements prior to extubation showed preexisting LV systolic dysfunction could predict extubation. A higher E/e post-extubation was associated with chances of reintubation. A larger study is indicated in developing a predictive model for extubation from echo parameters.

\section{REFERENCES}

1. Epstein SK. Weaning from ventilatory support. Current opinion in critical care 2009;15:36-43.

2. Boles JM, Bion J, Connors A, Herridge M, Marsh B, Melot C, et al. Weaning from mechanical ventilation. European Respiratory Journal 2007;29:1033-56.

3. Heunks LM, van der Hoeven JG. Clinical review: The ABC of weaning failure-a structured approach. Critical Care 2010;14:245.

4. Rothaar RC, Epstein SK. Extubation failure: magnitude of the problem, impact on outcomes, and prevention. Current opinion in critical care 2003;9:59-6.

5. Pinsky MR. Heart lung interactions during mechanical ventilation. Current opinion in critical care 2012;18:256-60.

6. Dres M, Teboul JL, Monnet X. Weaning the cardiac patient from mechanical ventilation. Current opinion in critical care 2014;20:493-8.

7. Teboul JL. Weaning-induced cardiac dysfunction: where are we today?. Intensive care medicine 2014;40:1069-9.

8. Saleh M, Vieillard-baron A. On the role of left ventricular diastolic function in the critically ill patient. Intensive Care Medicine 2012;38:189-91

9. Lemaire F, Teboul JL, Cinotti L, Giotto G, Abrouk F, Steg $\mathrm{G}$, et al. Acute left ventricular dysfunction during unsuccessful weaning from mechanical ventilation. Anesthesiology1988;69:171-9.

10. Lamia B, Maizel J, Ochagavia A, Chemla D, Osman D, Richard $\mathrm{C}$, et al. Echocardiographic diagnosis of pulmonary artery occlusion pressure elevation during weaning from mechanical ventilation. Critical care medicine2009;37:1696-701.

11. de Meirelles Almeida CA, Nedel WL, Morais VD, Boniatti MM, de Almeida-Filho OC,et al. Diastolic dysfunction as a 
predictor of weaning failure: A systematic review and metaanalysis. J Crit Care 2016;34:135-41.

12. Yang KL, Tobin MJ. A Prospective Study of Indexes Predicting the Outcome of Trials of Weaning from Mechanical Ventilation. Survey of Anesthesiology 1992;36:18.

13. Saugel B, Rakette P, Hapfelmeier A, Schultheiss C, Phillip $\mathrm{V}$, Thies $\mathrm{P}$, et al.Prediction of extubation failure in medical intensive care unit patients. Journal of critical care 2012;27: 571-7.

14. Esteban A, Frutos F, Tobin MJ, Alía I, Solsona JF, Valverdu $\mathrm{V}$, et al.A comparison of four methods of weaning patients from mechanical ventilation. New England Journal of Medicine1995;332:345-50.

15. Thille AW, Richard JC, BrochardL. The decision to extubate in the intensive care unit. American journal of respiratory and critical care medicine 2013;187:1294-302.

16. Nagueh SF, Smiseth OA, Appleton CP, Byrd BF, Dokainish $\mathrm{H}$, Edvardsen $\mathrm{T}$, et al. Recommendations for the evaluation of left ventricular diastolic function by echocardiography: an update from the American Society of Echocardiography and the European Association of Cardiovascular Imaging. European Journal of Echocardiography 2016;17:1321-60.

17. Caille V, Amiel JB, Charron C, BelliardG, Vieillard-Baron A, Vignon $\mathrm{P}$, et al.Echocardiography: a help in the weaning process. Critical care 2010;14:R120.

18. Voga, G. Early and simple detection of diastolic dysfunction during weaning from mechanical ventilation. Critical Care2012;16:137.

19. Cabello B, Thille AW, Roche-Campo F, Brochard L, Gómez FJ, Mancebo J, et al. Physiological comparison of three spontaneous breathing trials in difficult-to-wean patients. Intensive care medicine2010;36:1171-9.

20. Papanikolaou J, Makris D, Saranteas T, Karakitsos D, Zint- zaras E, Karabinis A, et al. New insights into weaning from mechanical ventilation: left ventricular diastolic dysfunction is a key player. Intensive care medicine2011;37:1976-85.

21. Moschietto S, Doyen D, Grech L, Dellamonica J, Hyvernat $H$, Bernardin G, et al. Transthoracic echocardiography with Doppler tissue imaging predicts weaning failure from mechanical ventilation: evolution of the left ventricle relaxation rate during a spontaneous breathing trial is the key factor in weaning outcome. Critical care2012;16:R81.

22. Roche-Campo F, Bedet A, Vivier E, Brochard L, Dessap AM. Cardiac function during weaning failure: the role of diastolic dysfunction. Annals of intensive care 2018;8:2.

23. Gillebert TC, Leite-Moreira AF, De Hert SG. Load dependent diastolic dysfunction in heart failure. Heart failure reviews 2000;5:345-5.

24. Thille AW, Boissier F, Ghezala HB, Razazi K, Mekontso-Dessap A, Brun-Buisson C, et al. Risk factors for and prediction by caregivers of extubation failure in ICU patients: a prospective study. Critical care medicine2015;43:613-620.

25. Dres M, Teboul JL, Anguel N, Guerin L, Richard C, Monnet X. Passive leg raising performed before a spontaneous breathing trial predicts weaning-induced cardiac dysfunction. Intensive care medicine 2015;41:487-4.

26. Liu J, Shen F, Teboul JL, Anguel N, Beurton A, Bezaz N, Richard C, Monnet X. Cardiac dysfunction induced by weaning from mechanical ventilation: incidence, risk factors, and effects of fluid removal. Critical Care 2016;20:369-7.

27. Mayo P, VolpicelliG, Lerolle N, Schreiber A, Doelken, P, Vieillard-Baron, et al. Ultrasonography evaluation during the weaning process: the heart, the diaphragm, the pleura and the lung. Intensive care medicine2016;42:1107-7. 